\title{
When is the preponderance of the evidence standard optimal?
}

\author{
Lando, Henrik
}

Document Version

Final published version

Publication date:

2002

License

CC BY-NC-ND

Citation for published version (APA):

Lando, $\mathrm{H}$. (2002). When is the preponderance of the evidence standard optimal?

Link to publication in CBS Research Portal

\section{General rights}

Copyright and moral rights for the publications made accessible in the public portal are retained by the authors and/or other copyright owners and it is a condition of accessing publications that users recognise and abide by the legal requirements associated with these rights.

\section{Take down policy}

If you believe that this document breaches copyright please contact us (research.lib@cbs.dk) providing details, and we will remove access to the work immediately and investigate your claim. 


\section{Center for Law, Economics and Financial Institutions at CBS}

LEFIC WORKING PAPER 2002-07

WHEN IS THE PREPONDERANCE OF THE EVIDENCE STANDARD OPTIMAL?

Henrik Lando

www.cbs.dk/LEFIC 


\title{
When is the Preponderance of the Evidence Standard Optimal?
}

\author{
Henrik Lando, \\ Department of Industrial Economics and Strategy \\ Copenhagen Business School, \\ e-mail: hl.ivs@cbs.dk
}

\begin{abstract}
This paper defines the preponderance of the evidence standard and establishes it as a benchmark, optimal under certain idealized conditions. The main conditions are: only efficiency matters (not fairness); people are risk-neutral; sanctions are socially costless; and a suit may be brought even if no violation of the law has occurred.

Concerning the definition of preponderance of the evidence, a distinction is made between standards based on probability of guilt and standards based on the evidence. It is stressed that the latter does not include ex-ante information concerning the offender's type, and should hence not be associated with a probability of guilt in a Bayesian sense.
\end{abstract}




\section{Introduction}

Different standards of proof are employed in different kinds of legal disputes. Beyond a reasonable doubt is the standard mainly used in criminal law, proof by clear and convincing evidence is the standard required e.g. for civil commitment of the mentally ill ${ }^{1}$, while preponderance of the evidence is generally held to be the standard employed in civil cases, e.g. involving breach of contract. In the law and economics literature one finds relatively little (systematic) work that discusses how these standards should be defined and understood, or that determines when each should be applied ${ }^{3}$.

This paper investigates the preponderance of the evidence standard. The aim is to make clear what preponderance of the evidence means and when it is optimal. By defining the circumstances under which it is optimal, it will also become clear when the standard is not appropriate, namely when the circumstances do not apply.

It is important to define the setting to which the present analysis applies. We shall assume that a potential offender may choose either to obey or to break the $1 \mathrm{aw}^{4}$; either action fixes a probability distribution over a set of signals that a court will observe, as in the standard moral hazard model. The court will, if a suit is brought before it, compare the weight of the information it receives with its standard of proof (or "proof burden"). Suit may be brought either by a law enforcement agent (such as a police officer who monitors car-driving) or by an aggrieved party (such as a party to a contract who may have observed a signal indicating breach). We will assume that everyone will observe the same signal ${ }^{5}$; this assumption implies that the outcome of a trial will be predictable (if the signal meets the proof burden there will be conviction); hence there will be no trial, -only settlement-, and we can ignore litigation costs ${ }^{6}$. To simplify further, we will assume that the effort spent by the enforcement agent or the aggrieved party in gathering information (in retrieving the signal) is exogenous ${ }^{7}$. In the setting just described, I will show that preponderance of the evidence is optimal under the following further

\footnotetext{
${ }^{1}$ or e.g. for proof of actual malice in public figure libel cases.

${ }^{2}$ Much of the work related to the standard of proof discusses the consequences for optimal enforcement of imperfect information concerning "guilt". For articles that discuss the optimal standard of proof per se, see e.g. Davis [2], Miceli [7], Pug [8], Posner [9], Schauer and Zeckhauser [10] and Schrag and Scotchmer [11].

${ }^{3} \mathrm{ln}$ particular, I have not found work that places the analysis of the optimal standard of proof within the theoretical framework developed by e.g. Kaplow [3], Shavell [13], and Polinsky [14], following Becker's seminal article [1].

${ }^{4}$ In a broad sense, including e.g. performing a contract, taking due care, or adhering to a rule such as a speeding limit.

5 in reality, of course, an enforcement agent or an aggrieved party may not be able to correctly predict what information the court will eventually possess.

${ }^{6}$ See Shavell and Polinsky [14] for an analysis of how legal error may affect incentives to obey the law and incentives to litigate. They assume that the court may receive a different signal than that of the parties, so litigation may occur.

${ }^{7}$ In reality it may be determined in part by the proof burden; however, this complication will be ignored in our context.
} 
assumptions: only efficiency matters (fairness does not matter); people are risk-neutral; sanctions are socially costless to impose; and a signal of a wrong committed may be emitted even if no violation of the law has occurred ${ }^{8}$. This part of the paper can be summarized in the statement that preponderance of the evidence maximizes deterrence.

At the conceptual level, I will argue that preponderance of the evidence should be distinguished from a standard that finds the defendant guilty when the probability of guilt is higher than $50 \%$. Some authors fail to make this distinction. For example, Schauer and Zeckhauser [10] write (p.33):

"We take the preponderance of the evidence standard as equivalent to a .5 , proof, beyond a reasonable doubt as roughly .95 , and proof by clear and convincing evidence even more roughly as perhaps .75".

However, a standard of evidence does not refer to the probability of guilt but only to the weight of the evidence. The former includes ex-ante information concerning the offender's type, as will be further discussed below.

The structure of the paper is as follows: The preponderance of the evidence standard is first defined. Second, the argument is made why this standard under certain conditions maximizes deterrence. Third, this argument leads naturally to a discussion of the conceptual distinction between standards of evidence and standards of guilt. Fourth, we return to the assumptions under which preponderance of the evidence is optimal. Comments and a summary end the paper.

\section{Definition}

The preponderance of the evidence standard can be defined as the standard that sanctions whenever the evidence of the case (i.e. the set of received signals) is relatively more likely to be received when a violation has occurred than when it has not ${ }^{9}$. A bit of notation is useful here. Let the evidence in a given case be $x$. Let $p$ be the probability, at the time of the action, that this evidence will be realized if the illegal ${ }^{10}$ act is committed, and let $q$ be the probability that $x$ will be produced if the illegal act is not committed. Then preponderance of the evidence will be defined to mean that a sanction will be applied if and only if $p$ is greater than $q$.

This raises the question what evidence means. I shall interpret evidence as signals concerning actions, excluding e.g. information concerning race, social class, or other kinds of information

\footnotetext{
${ }^{8}$ The arguments in this paper will be verbal not mathematical; for mathematical proofs see my working paper [5].

${ }^{9}$ In technical terms this means that the sanction should be applied when the likelihood ratio exceeds one.

${ }^{10}$ For convenience, the term illegal is used even though we may be dealing with e.g. a breach of contract.
} 
concerning the type of actor involved. As an example, information showing that the defendant is a repeat-offender is not part of the evidence according to this definition; it is ex-ante information concerning type. Witness-testimony on the other hand is evidence.

The distinction is whether a given piece of information is in itself informative of those actions that are in dispute.

\section{Why preponderance of the evidence maximizes deterrence}

It will now be argued that preponderance of the evidence, as just defined, maximizes deterrence ${ }^{11}$.

Using the notation above, this follows from the fact that if $\mathrm{p}>\mathrm{q}$ for the evidence $x$ in a given case, then $p * s>q * s$, where $s$ is the (positive) sanction. This means that preponderance of the evidence ensures that the expected sanction will be higher when the illegal act has been performed than when it has not. When this is the case, the existence of a sanction will act as an inducement not to break the law. Conversely, if $\mathrm{p}<\mathrm{q}$ for some other evidence $y$, then no sanction should be applied, since the nosanction outcome then occurs with higher probability when the legal rather than the illegal act has been undertaken. The point is that the court should respond to any given signal in such a way that when the potential offender contemplates the response of the court to the signal, the offender is swayed in the direction of obeying the law.

Thus, preponderance of the evidence maximizes deterrence, but it is not always the case that maximal deterrence is optimal, as we shall discuss below. However, before turning to this point it is worth elaborating on what preponderance of the evidence means in terms of the kind of information that a court should use (and, equally important, should not use) in reaching a verdict.

\section{On the non-use of ex-ante information}

One easily takes for granted that a judge should establish the probability of guilt. The implicit notion behind this view is (in a Bayesian world) that the judge should up-date prior beliefs concerning "guilt" with the weight of the evidence in order to arrive at the (ex-post) probability of guilt. To express this mathematically, when $A$ expresses the ex-ante beliefs (the a priori likelihood that a person of a given "type" would commit the act in question) and $L$ is the likelihood ratio (the weight of the evidence), the task of the judge is seen as establishing final beliefs about guilt, $\mathrm{P}$, where Bayes' law establishes that $P=A * L$. However, as just argued, only $L$ is relevant when the aim is deterrence: when only deterrence

\footnotetext{
${ }^{11}$ This result is shown formally in my working paper [5].
} 
matters ex-ante probabilities of guilt or innocence should play no role in deciding whether to impose a sanction.

This distinction between the probability of guilt and the likelihood ratio is worth highlighting, since it is easy to confound the two. The likelihood ratio seems to be concerned with the probability that the defendant did commit the act or did not, but this impression can be deceptive. To see this, consider the simple textbook moral hazard model. The principal will know which action the agent takes (e.g. either high or low effort), but will still optimally commit to sanctioning the agent if the likelihood ratio indicates low effort. In this deterministic model, there is no uncertainty concerning actions, so from this it can be seen that the likelihood ratio does not express the likelihood that low or high effort was undertaken.

To see that this distinction has real world implications, e.g. for the law of evidence ${ }^{12}$, consider the following example. Let there be a society in which subcultures A and B differ in their propensity for crime. Imagine that very few people in A even consider committing theft while almost everyone in B commits theft if it is to their (amoral) personal advantage. Imagine further that a person from either subculture is apprehended by the police, and that the evidence (as defined above) raised against them turns out to be identical. If the aim of sanctioning is deterrence, should a court then treat the two cases in the same way even though the probability of guilt is different in the two cases? According to the result above, the answer is yes. The verdict should in both cases be "guilty" when the evidence before the judge is more likely to be the outcome of a theft than not. It may seem surprising that the optimal system in this way totally disregards ex ante probabilities, but note that if we assume that the payment of a fine is a mere transfer of value, and in this sense costless to society, then it may be worthwhile to impose a fine even when it is unlikely in a Bayesian sense that a person is guilty. The point is that applying the preponderance of the evidence standard constitutes a costless way for society of maximizing deterrence of the few potential offenders in subculture A.

We now turn to the question when maximal deterrence is optimal, or, put differently, when preponderance of the evidence is an optimal standard.

\section{When is preponderance of the evidence optimal?}

\section{No risk-aversion}

When social welfare includes only efficiency and not fairness, whether or not potential offenders are risk-averse does not affect the result that preponderance of the evidence maximizes deterrence. This can

\footnotetext{
${ }^{12}$ For example for the issue whether or not to allow character-evidence in court. This question is analyzed by Schrag and Scotchmer [11], but note that their set-up is different from that presented here. As argued in the section below concerning whether or not investigations may take place when there is no offense.
} 
be seen clearly in the case where there are only two outcomes (either a person must pay a sanction or not); in this case risk-aversion or concavity of the utility function implies only that the difference between the utility in these two states is increased (loosely speaking). It is then intuitive that the rationale of the preponderance of the evidence standard, as put forward above, remains true. More generally, also for a risk-averse agent a sanction deters an action if and only if the sanction is applied with greater probability if the action has been performed.

However, when people are risk-averse, the imposition of a fine becomes socially costly in terms of risk-bearing, and for this reason it will generally be optimal for society to sanction in fewer states. Some deterrence will hereby be lost but this effect will be small when the probability of the state is nearly the same whether or not an illegal act has been committed. In comparison, the effect on risk-bearing of no longer sanctioning in such a state will not in the same way be negligible; it will be a first-order effect.

The tradeoff between deterrence and risk-bearing which emerges when potential offenders are riskaverse is well-known from the moral hazard literature, and will hence not be mentioned further here.

\section{Zero social cost of imposing penalties}

As when people are risk-averse, when it is costly to impose sanctions, this will tend to make the optimal standard stricter; the benefit of sanctioning in some state of nature must be balanced by the cost of so doing. For those states of nature that occur with only a slightly increased probability if the unlawful act is committed, the cost of sanctioning renders it useless to sanction, even though sanctioning would increase deterrence (slightly). The cost of sanctioning should here be interpreted in a wide sense, including e.g. the costs of litigation ${ }^{13}$.

\section{Investigations may occur even if there is no unlawful action}

Even if people could be assumed to be risk-neutral and sanctions could be assumed to be simply transfers of wealth, there would remain an important set of circumstances for which it is misleading to think of preponderance of the evidence standard as an optimal standard of proof. This class of cases has not, in my view, been sufficiently noted in the existing literature.

Consider as an example the choice facing a potential murderer: If he or she decides not to commit murder, there will be no victim, hence no investigations and hence no possibility of an unfair conviction. Hence, the possibility of an unfair verdict should not affect his or her incentives. Naturally, he or she may fear being unfairly convicted for a crime committed by someone else, but this possibility remains if

\footnotetext{
${ }^{13}$ For the case where litigation is costly, see Shavell and Polinsky [14].
} 
he or she commits the first-mentioned crime. If being sanctioned for two offences is twice as bad as being sanctioned for one (which will of course not necessarily be the case; for instance, one of the sanctions may be the death penalty or stigma may enter), then the probability of an unfair conviction should not affect the incentives of the potential murderer. In other words, the incentives of the potential murderer are only affected by the possibility of an unfair conviction if he or she thinks that investigations may take place even if he or she does not commit the murder, and that is highly implausible. Thus, it is only for such offenses where investigations may take place independent of the wrongful act, that our rationale for the preponderance of the evidence standard applies ${ }^{14}$. Such offences include e.g. speeding in traffic; causing an accident through careless driving (where the accident may occur even if one drives with care; this was Png's example); committing some other tort; or breaching a contract.

\section{Discussion}

It may be asked whether the preponderance of the evidence standard remains optimal when the possibility is opened up that the sanction could depend on the weight of the evidence. It was implicit in the arguments above that a sanction is either applied or not.

It turns out that the answer is affirmative. In the above example when $p>q$, the sanction should be maximal $^{15}$ to maximize deterrence ${ }^{16}$, and when $\mathrm{p}<\mathrm{q}$ the sanction should be minimal, i.e. zero, to maximize the incentive to perform. When only deterrence matters, there is no reason to graduate sanctions.

This raises another question: May preponderance of the evidence not lead to over-deterrence if the sanction is set at a very high level as it should be according to Becker's [1] analysis of the case of riskneutrality? From a utilitarian viewpoint, the expected sanction should be no higher than the externality created by the unlawful act, and one can imagine that if the sanction and the probability of apprehension are very high, it may be optimal to lower deterrence by adopting a different standard of proof than preponderance of the evidence. However, given the assumptions of risk-neutrality and costless litigation and sanctioning, it will be preferable to save resources on enforcement (e.g. on monitoring traffic) to bring down deterrence to its optimal level, rather than to change the standard of proof. Given our main

\footnotetext{
${ }^{14}$ Schrag and Scotchmer [11] find that the possibility of an unfair conviction may affect the incentives of a person considering whether or not to commit murder but their analysis rests on the assumption that the murderer will think that if he/she does not kill a given person (in a dark alley) somebody else might kill that same person, and the blame may then still be on him/her. While this situation may occur it seems, as the authors admit in an accompanying paper [12], somewhat contrived.

${ }^{15}$ We have implicitly assumed that the sanction is set at some maximal level perhaps determined by the wealth of individuals, and that over-deterrence is not an issue.

${ }^{16}$ in line with Becker's [1] result that maximal sanctions are optimal when agents are risk-neutral, see Kaplow-
} 
assumptions, adopting the preponderance of the evidence standard maximizes deterrence with no social cost while it is clear that law enforcement in the form of monitoring of behavior is not without $\operatorname{cost}^{17}$.

\section{Summary}

This article has put forward a simple incentive argument in favor of preponderance of the evidence: it maximizes deterrence since it maximizes the difference in expected utility between adhering to and violating the law. This establishes preponderance of the evidence standard as a benchmark in civil law. However, maximal deterrence is not the only aim of the legal system. When fairness is an important concern, when agents are risk-averse, and when litigation and the imposition of a sanction are socially costly, preponderance of the evidence will no longer be optimal. The standard will then have to be modified to take these factors into account.

Furthermore, it was stressed that the incentive argument makes little sense when investigations do not occur at all when there has been no violation of the law. This is often the case for criminal acts such as e.g. murder.

At the conceptual level, it was stressed that preponderance of the evidence should be distinguished from standards referring to probability of guilt (which is the case for the criminal law standard of "beyond a reasonable doubt", see e.g. Miceli [7]. Preponderance of the evidence relies only on the evidence and not on ex-ante information concerning type. Since it ignores ex-ante probabilities of guilt, it may have only little to do with the probability of guilt in a Bayesian sense.

\section{References}

[1] Becker, Gary: "Crime and Punishment: An Economic Approach", Journal of Political Economy, 1968, 76 (2), pp. 169-217.

[2] Davis, Ni: "The Value of the Truth and the Optimal Standard of Proof in Legal Disputes", Journal of Law, Economics and Organization, October 1994, vol. 10, no. 2.

[3] Kaplow, Louis: "The Value of Accuracy in Adjudication: An Economic Analysis", Journal of

\footnotetext{
Shavell [13].

${ }^{17}$ Litigation is not without cost in reality, but note that part of the cost is born by the litigants themselves. How to set the standard of proof when litigation is costly is left for future research.
} 
Legal Studies; 23(1), Part 2 Jan.1994, pp. 307-401.

[4] Lando, Henrik: "An Attempt to Incorporate Fairness in an Economic Model of Tort Law", International Review of Law and Economics, vol.17, No.4, (December 1997), pp.575-587.

[5] Lando, Henrik: "The Optimal Standard of Proof When Both Fairness and Deterrence Matter", Working Paper, Department of Finance, Copenhagen Business School, 00-6. (see $<\mathrm{http} / / /$ www.cbs.dk/staff/hlando/\#d.\%20Recent\%20working $>$ ).

[6] Miceli, Thomas J: "Optimal Criminal Procedure: Fairness and Deterrence", International-Reviewof-Law-and-Economics; 11(1), May 1991, pages 3-10.

[7] Miceli, Thomas: "Optimal Prosecution of Defendants Whose Guilt Is Uncertam", Journal of Law, Economics and Organization; 6(1), spring 1990, pp. 189-202.

[8] Png, Ivan: "Optimal Subsidies and Damages in the Presence of Judicial Error", International Review of Law and Economics 1986. Vol. 6, No.1, pp. 101-105.

[9] Posner, R: "An Economic Approach to the Law of Evidence", John M. Olin Law and Economics working Papers No. 66, 2000, downloadable from http://www.law.uchicago.edu/Publications/Working/index.html

[10] Schauer F. and Zeckhauser R.: "On the Degree of Confidence for Adverse Decisions" Journal of Legal Studies, vol. XXV (January 1996).

[11] Schrag, J. and Scotelimer S.: "Crime and Prejudice: The Use of Character Evidence in Criminal Trials", Journal of Law, Economics and Organization, October 1994, vol. 10, no. 2.

[12] Schrag, J. and Scotchmer S: "The Self-Reinforcing Nature of Crime", International Review of Law and Economics, September 1997, vol. 17, iss. 3, pp. 325-35.

[13] Kaplow, Louis and Shavell, Steven: "Accuracy in the Determination of Liability", Journal-of-Lawand-Economics; 37(1), April 1994, pp. 1-15.

[14] Shavell, Steven and Polinsky, A. Mitchell: "Legal Error, Litigation, and the Incentive to Obey the Law", Journal-of-Law,-Economics-and-Organization; 5(1), Spring 1989, pp. 99-108. 